\title{
Psychiatric diagnoses as grounds for disability pension among former child welfare clients
}

\author{
Miia Bask \\ Tiina Ristikari \\ Ari Hautakoski \\ Mika Gissler
}

\author{
Norwegian Social Research, Norway \\ miia.bask@nova.hioa.no \\ National Institute for Health and Welfare, Finland \\ National Institute for Health and Welfare, Finland \\ National Institute for Health and Welfare, Finland; University of Turku, Finland, and \\ Karolinska Institute, Sweden
}

(Received March 2017 Revised May 2017)

http://dx.doi.org/10.14301/llcs.v8i4.459

\begin{abstract}
This study used the 1987 Finnish Birth Cohort, which included all children born in Finland in 1987 $(N=59,476)$, to investigate psychiatric diagnoses as grounds for disability pensions (DPs) among child welfare clients and explored the background factors associated with such diagnoses. Descriptive statistics show that DP is substantially more common among child welfare clients than among other children.

Logistic regressions revealed that the factors most strongly related to psychiatric diagnoses among girls were mother's somatic DP, child protection history, and parental social assistance. Psychiatric diagnoses among boys were most strongly related to mother's psychiatric DP, child protection history, and parental divorce.

The factors related to DP among girls included child protection history, father's psychiatric DP, father's somatic $D P$, and parental social assistance. DP among boys was related to child protection history, mother's psychiatric DP, parental social assistance, father's somatic DP, and father's psychiatric care in specialised hospitals.

A child welfare history that includes out-of-home care indicates that there were severe problems in the home environment during upbringing. Detailed investigations should therefore be undertaken, such as examining the role of mediating and moderating factors, including the ability of social and educational services to ameliorate the effects of challenging childhood conditions.
\end{abstract}

\section{Keywords}

Child welfare, disability pension, Finland, out-of-home care, psychiatric diagnoses

\section{Introduction}

States with generous welfare systems have become increasingly concerned about the future financing of pension systems. Because of aging populations in many industrialised countries, the working population must remain in the workforce longer to keep the welfare and pension systems afloat. It is therefore important to both the research community and decision-makers to identify the causes of the disbursement of disability pensions (DPs) to younger recipients. Thus, there is a need for more detailed knowledge regarding the factors underlying DP decisions.

More importantly, young recipients of DP are at risk for economic hardship later in their lives. This is because they contribute to (and later benefit from) the earnings-based occupational pension insurance. 
If their work career is short, payments in the future will be small. There is substantial evidence regarding child welfare clients' experience of intergenerational transmission of inequality and their disadvantaged positions in adulthood. Previous research has shown that individuals with a childhood history in social services are more disadvantaged than their counterparts in many areas of life, including labour market integration (Vinnerljung, Brännström, \& Hjern, 2015). However, to our knowledge, no previous research has investigated the specific diagnoses that underlie DP decisions for individuals who have childhood histories with social services. Therefore, our objective is to investigate psychiatric diagnoses as grounds for DP among child welfare clients, exploring whether child welfare clients are more prone to DP on specific psychiatric grounds than their counterparts, and to scrutinize the background factors related to psychiatric diagnoses and DP.

Emergency out-of-home care placements in Finland increased during the early 2000s but began to decrease between 2013 and 2014. Altogether, 10,675 children were placed in care during 2014, which represents $1 \%$ of the population of this age group (0-17 years). In total, 17,958 (1.1\%) children and youth were placed outside of their homes in 2014. Of these placements, 53\% were male. More than half of these children were placed with foster families; of these, $13 \%$ were placed with their relatives (THL, 2014a, 2014b).

Short-term absence from the labour market due to health reasons is typically covered by sickness allowance in Finland. However, individuals with permanently reduced work capacities are entitled to DP. If the disability lasts less than one year, a sickness allowance is paid by the Social Insurance Institution. If the illness, injury or handicap reduces work capacity for a year or more, an individual is compensated by cash rehabilitation benefits or DP (for a more detailed description, see ETK, 2017). During a fixed-term DP, an individual may be offered rehabilitation or an opportunity to change occupation if the pension provider considers that there are possibilities to return to work. The process leading to permanent DP typically involves thorough medical examinations to evaluate the capacity for work. Even if the majority of the DPs granted to the cohort in this paper are fixed-term, individuals with a fixed-term DP tend to depart from the work force permanently.

In 2014, there were 232,475 individuals on DP in Finland. Of these, 1,615 were under 20 years of age, and 43,129 were between 20 and 44 years old. The most common grounds for DP are mental health and behavioural diagnoses. This group of diagnoses includes mental and behavioural disorders due to psychoactive substance abuse; schizophrenia, schizotypal and delusional disorders; mood affective disorders; neurotic, stress-related and somatoform disorders; and disorders of psychological development and intellectual disability (ETK, 2015, p. 137). These diagnoses are particularly common among younger DP recipients; 32,779 individuals between 16 and 44 years old are on DP due to mental health and behavioural diagnoses (ETK, 2015).

The share of new retirees granted DP in Finland has decreased. However, the share of mental health problems as grounds for DP is substantial. A total of 20,987 individuals were granted DP in 2014; within this group, 6,757 individuals were granted DP due to mental health and behavioural problems. Moreover, 3,575 of these were between 16 and 44 years old (ETK, 2015, p. 114).

Because mental health and behavioural issues are the main reasons for DP among younger DP recipients in Finland, these diagnoses are of considerable interest. Moreover, there is substantial political concern regarding the working abilities of the working-age population because aging and high unemployment are already challenging the sustainability of the Nordic welfare state model in Finland. This threatens to place larger numbers of individuals in conditions of economic hardship when they reach old age retirement. We hope that this research can shed light on the challenges child welfare clients experience in their transition to the labor market and increase interest in developing measures to support these children in this transition.

\section{Previous research}

\section{Intergenerational transmission of inequality}

In their review, Ben-Shlomo and Kuh (2002) discuss several factors that affect an individual's health over the life course. The mechanisms behind the intergenerational transmission of inequality include parents passing on economic, human and cultural capital. Two classes of models of adult 
health appear in the life course literature. The first class is called critical period models. These models emphasise the timing of an experience, meaning that exposure to a certain experience during a particular period in an individual's development can have long-term consequences on the physiological functions of the individual and may lead to ill health. Thus, poverty may be particularly harmful to children during important life course transitions such as the beginning of school.

The other class of models concentrates on accumulated risk factors and experiences. These models emphasise the accumulation of effects over the individual life course. In some cases, the main element is the number of risk factors, whereas in other cases, it is the duration of the risk-experience that matters (Ben-Shlomo \& Kuh, 2002; Lynch \& Smith, 2005).

The processes that lead a disadvantaged youth to DP can be described as cumulative disadvantage. The cumulative advantage model proposed by Crystal and Shea (1990) is a popular model in lifecourse research that has achieved widespread acceptance in the literature. In attempting to explain inequality in society, the cumulative advantage model focuses on how inequality can be exaggerated over the life course because individuals accumulate different amounts of advantages and disadvantages over time: "Those who are initially advantaged [...] are more likely to receive a good education, leading to good jobs, leading to better health and better pension coverage, leading to higher savings and better postretirement benefit income" (p. 437). Correspondingly, those who are disadvantaged from the start are less likely to receive these types of positive reinforcement, resulting in increased intra-cohort inequality over the life course (Bask \& Bask, 2015). This model also portrays the phenomena discussed in this paper. A history with child welfare services is itself an indicator of negative life experiences early in the life course. DP is an additional indicator of a disadvantaged position that involves worse health and worse pension coverage. Furthermore, we consider the accumulated risk factors that the parents of the children in our study possess to study intergenerational transmission of disadvantage.

A substantial body of literature demonstrates that poor socioeconomic conditions during the early life course affect adult health. In her review of the literature, Reiss (2013) shows that children from disadvantaged socioeconomic backgrounds are clearly more prone to mental health problems. The review further shows that the persistence of low socioeconomic status (SES), usually measured as a combination of parental educational, economic and occupational status, is related to higher rates of mental health problems. Studies show that accumulated risk factors have more severe consequences than exposure to a single risk factor for the development process over the early life course, and the dangerousness of the effects increases with the sum of the risk factors. Therefore, even when an individual shows extraordinary resilience in many cases, exposure to multiple risks has a permanent effect on the individual (Evans, Li, \& Whipple, 2013; Franzén, Vinnerljung, \& Hjern, 2008; Lynch \& Smith, 2005).

Evans and Cassells (2014) show that children who experience poverty in their early childhood follow a developmental trajectory that involves worse behavioural adjustment. Cumulative risk experience is found to be an explanatory factor. More specifically, these authors link early childhood poverty to behavioural adjustment problems in early adulthood by showing that longer periods of poverty at age nine correlate positively with worse mental health at age 17. Moreover, there is recent evidence that early childhood poverty has a negative effect on mental wellbeing in adulthood and that cumulative risk experience acts as an explanatory mechanism linking childhood poverty and young adulthood mental health problems (see also Costello, Erkanli, Copeland, \& Angold, 2010; Najman et al., 2010; Paananen, Ristikari, Merikukka, \& Gissler, 2013).

Multiple studies have shown that individuals' socioeconomic background affects adult health and wellbeing outcomes (Ristikari, Hakovirta, \& Gissler, 2016). SES also influences physical and psychosocial living conditions. Parents with fewer resources can often afford only disadvantageous living conditions, including lower-quality schools and more dangerous and segregated neighborhoods for their children (Cohen, Janicki-Deverts, Chen, \& Matthews, 2010). In addition to SES, another background factor that has been shown to be important is family type. After controlling for several relevant explanatory factors, a Swedish study showed that children of single mothers are clearly more likely to enter outof-home care (Franzén et al., 2008). 
Parents who are struggling to make ends meet have fewer resources - both economic and noneconomic - to offer their children. Parental SES influences parents' expectations for their children, and these expectations, in turn, influence children's outcomes (Bask, Ferrer-Wreder, Salmela-Aro, \& Bergman, 2014). Thus, values and expectations are transmitted from parents to their children. Some studies indicate that there is a certain social inheritance in welfare program participation. The probability of an individual becoming dependent on welfare programs is higher for those whose parents were also welfare recipients. A Norwegian study shows that the norms and values related to DP are passed on from one generation to the next and that the probability of receiving DP is partly dependent on parental behaviour regarding DP (Bratberg, Nilsen, \& Vaage, 2015; see also Dahl, Kostøl, \& Mogstad, 2014).

The remainder of this paper is organised as follows. In the next section, we present previous research on child welfare clients and their mental health and on psychiatric diagnoses as grounds for DP. We then present our aims, materials and methods, and results before concluding the paper with a discussion.

\section{Child welfare clients and health}

There is substantial evidence that child welfare clients are disadvantaged in many areas of life. Child welfare clients have been shown to have higher rates of illness, particularly mental illness, but they also tend to be characterised by lower educational attainment (Berlin, Vinnerljung, \& Hjern, 2011; Jackson \& Cameron, 2012; Kestilä, Väisänen, Paananen, Heino, \& Gissler, 2012). They also have a higher likelihood of becoming involved in criminality; this is particularly true among children with a history of out-of-home care (Doyle, 2007; Mersky \& Janczewski, 2013). Child welfare clients are also overrepresented in statistics involving suicide (Farand, Chagnon, Renaud, \& Rivard, 2004; Vinnerljung, Hjern, \& Lindblad, 2006).

In their review of the relationship between SES and child health, Chen, Matthews, and Boyce (2002) present several potential mechanisms that link parental SES to children's health. In addition to prenatal factors, they present studies that reveal emotional/cognitive, social, environmental, behavioral and biological mechanisms that link parental SES with their children's health. For example, children from lower SES families have increased risk of injury, more severe and higher prevalence of asthma, and increased risk of high blood pressure. These children are also more likely to become smokers and to exercise less than their wealthier counterparts.

As discussed above, individuals with low SES have worse health than their wealthier counterparts. Low SES is also related to behaviours that are known to be health risks. For instance, smoking, excessive alcohol consumption and lower levels of physical activity vary based on SES. Although interest in the grounds and processes for entry into DP among the younger population has recently increased, there is scant research investigating the risk factors for young DP recipients because most disability studies address the older population (Bowen \& González, 2010).

Therefore, low parental SES background can be seen as a risk factor for health problems in the younger population. As previously discussed, studies of the determinants of DP are mainly focused on adulthood predictors of DP (Harkonmäki et al., 2007). However, children with a history of social services suffer from mental health problems more often than their counterparts do (Heneghan et al., 2013), which leads to the suspicion that child welfare clients are more prone to DP than children without that history and that psychiatric diagnoses may be important grounds for such DP decisions. To our knowledge, there are no studies that address these research questions.

\section{Psychiatric diagnoses as grounds for DP}

The number of DP recipients has remained stable in Finland since the final decades of the twentieth century. However, the share of the various grounds for entry into DP has changed. Since the mid-1990s, mental disorders have increased as the primary grounds for DP (Organisation for Economic Cooperation and Development, 2014).

According to the disability process model, disability is an outcome of a long-term process with great variability in illness types and severity as well as health behaviours and personal and environmental factors (Verbrugge \& Jette, 1994). The relationship between adverse childhood living conditions and DP has been documented in previous research (Upmark, Lundberg, Sadigh, \& Bigert, 2001; Upmark \& Thundal, 2002).

In a recent study, Laaksonen, Blomgren, and Tuulio-Henriksson (2016) show that sickness allowances due to mental health problems 
predicted DP based on mental health grounds. Negative factors seem to accumulate; for example, bipolar disorder often involves other types of problems, such as excessive alcohol consumption. This accumulation of problems negatively affects the labour market prospects of these individuals. Sickness allowances due to mental disorders also predicted DP in cases of schizophrenia and depression. A Norwegian study showed that anxiety and depression were significant factors that explained subsequent DP. In addition to the separate effects, the combination of depression and anxiety was an even stronger explanatory factor for DP. These factors were more noticeable in the younger population (Mykletun et al., 2006).

\section{Aims}

There is a vast body of literature on this topic. We know a great deal about the life courses of child welfare clients, and we know a great deal about psychiatric diagnoses as grounds for DP in the general population. However, no studies have examined specific psychiatric diagnoses as the grounds for DP among former child welfare clients with a history of out-of-home care. Therefore, this study aims to investigate psychiatric diagnoses as grounds for DP among child welfare clients and to explore the background factors that are related to psychiatric diagnoses and DP. Furthermore, we consider the cumulative risk assumption and test whether multiple risk factors increase the likelihood of DP within this cohort. The motivation for this research is to gain greater insight into the adult life course, labour market attachment and psychiatric challenges related to that transition among the very vulnerable group of child welfare clients.

\section{Materials and methods}

\section{Study population}

The study uses the 1987 Finnish Birth Cohort (Paananen et al., 2013). The data include all children born in Finland in $1987(\mathrm{~N}=59,476)$ and their parents. Children who died before the age of 18 were removed from the analyses in this paper. The children's life courses until the age of 25 were followed using official registers. The study was approved by the Ethical Committee of the National Institute for Health and Welfare (\$28/2009) and received appropriate permission to use the confidential register data in scientific research from all register-keeping organisations.

For the purposes of this study, we use data on the members of the cohort who were subjected to child welfare actions at some point during their lives. The data describe their life conditions prior to age 16, including information about the health and education of the parents of the cohort members, information about child welfare actions, and information regarding the diagnostic grounds for the DP received by the cohort member. All register data were combined using the unique personal identification numbers (IDs).

\section{Study variables}

Child protection. Data on child welfare actions were obtained from the National Institute for Health and Welfare, Child Protection Register. In our analyses, we use information about whether the cohort member has a history of out-of-home care. In total, 1,891 individuals in this cohort had been subjected to child welfare actions (see more details in Table 1). Child welfare actions include support community care, out-of-home placement, including emergency and involuntary placement, and after-care. The average length of a single placement was 616 days.

Disability pension (DP). Cohort members' DP data were gathered from the Social Insurance Institution of Finland (2003-2012) and from the Pension Register that is maintained by the Finnish Centre for Pensions (2006-2012). The data included fixed-term DPs (891 individuals) and DPs that will continue until further notice (481 individuals). The data also included information about the diagnostic grounds for the DP using the ICD 10. DP data were gathered from age 16 onwards. This cohort included 1,372 individuals with DP, of whom 866 were granted DP based on psychiatric diagnoses (see more details in Table 1). Those with intellectual disability diagnoses (F70-F79) were removed from the regression analyses (Table 2a-2c) but are included in the analysis investigating whether child welfare clients are more prone to specific psychiatric DP grounds than their counterparts (Table 3 ).

Parents' DP data were also obtained from the Pension Register. Parental DPs were divided into two groups: somatic and psychiatric (F00-F99). Before the children turned 16 years old, 2,115 fathers were on DP based on somatic grounds and 1,173 based on psychiatric grounds. The 
corresponding figures for mothers were 969 and 907, respectively.

Parental psychiatric in-/outpatient care. The Finnish Hospital Discharge Register (HDR), which is maintained by the National Institute for Health and Welfare (THL), includes all inpatient care episodes from all Finnish hospitals since 1969 and all specialised-level outpatient visits in public hospitals since 1998. Data on parental psychiatric care were collected from the HDR for psychiatric inpatient care and/or outpatient care between the cohort member's birthdate and the date when the cohort member reached age 16 . In total, 3,031 fathers and 3,796 mothers had psychiatric hospital inpatient care episodes before the children turned 16 years old.

Parental social assistance. Recipients of social assistance are registered by the THL. Social assistance refers to last-resort financial assistance provided by social services to a household from municipal funds when other sources of income are insufficient to ensure that the basic needs of a person or a family are met. Parental social assistance was registered for either the biological mother or biological father or both parents during the follow-up 1987-2003 period. In total, 21,234 parents had received social assistance at least once before the children turned 16 years old.

\section{Family characteristics}

Mother's age under 20 years at the time of the child's birth. Data on the mother's age at the time of childbirth were obtained from the Medical Birth Register, maintained by the THL. In total, 1,884 mothers were under 20 years of age when the child was born.

Parental education. Data on the highest educational level of cohort members' parents when the cohort member was below 16 years old were obtained from Statistics Finland and classified as 'high school or higher' (12 years or more of education; 10,675 fathers and 9,383 mothers had this educational level), 'lowest level tertiary' (11 years; 8,121 fathers and 13,604 mothers), 'lower secondary' (10-11 years; 25,560 fathers and 26,600 mothers), or 'primary' (up to nine years; 14,540 fathers and 9,291 mothers).
Divorce. Data on cohort members' biological parents' divorces (classified in the analyses as divorced vs. not divorced during the follow-up) were obtained from the Finnish Central Population Register. This cohort comprises 13,327 cases in which biological parents were divorced before the child turned 16 years old.

Death of a parent. Information on parents' death during the follow-up was received from the Finnish Central Population Register. In total, 1,755 fathers and 595 mothers died before the child turned 16 years old.

Cumulative risk factors. This is a cumulative risk factor variable (i.e., Parents' social assistance; Mother's psychiatric in-/outpatient care; Father's psychiatric in-/outpatient care; Mother's psychiatric DP; Mother's somatic DP; Father's psychiatric DP; Father's somatic DP; Mother's death; Father's death; Divorce; and Mother younger than 20 years old). We found that 21,832 individuals had no risk factors, 26,768 had 1-2 risk factors, 8,773 had 3-4 risk factors, and 1,505 had 5-9 risk factors.

\section{Analysis}

The first part of the analysis involves logistic regressions that seek to determine whether DP is more likely among child welfare clients than among others. Binary logistic regression analyses were used to define the odds ratios (ORs) and 95\% confidence intervals $(95 \% \mathrm{Cls})$. The analyses were performed using SPSS Statistics version 24 . The first model involves child welfare experience as the only covariate. The second model includes all the covariates, and the third model differs from the second model by excluding the child welfare experience and reveals the relationship between DP and social background characteristics in this cohort. Model 4 investigates the role of the cumulative risk factors, and Model 5 involves cumulative risk factors and child welfare experience. Finally, we present crosstabs with $\chi^{2}$ and Fisher's tests to reveal whether specific psychiatric diagnoses are more common DP grounds among individuals with child welfare experience than among those without that experience. 


\section{Results}

The descriptive statistics of our empirical material are shown in Table 1.

\section{Table 1. Description of the dataset}

\begin{tabular}{|c|c|c|c|c|c|c|}
\hline & All $(59$ & & Boys & & Girls & 95) \\
\hline & $\mathrm{N}$ & $\%$ & $\mathrm{~N}$ & & $\mathrm{~N}$ & \\
\hline Disability pension & 1372 & 2.3 & 668 & 2.2 & 704 & 2.4 \\
\hline Disability pension with psychiatric diagnosis & 866 & 1.5 & 383 & 1.3 & 483 & 1.7 \\
\hline Child welfare & 1891 & 3.2 & 931 & 3.1 & 960 & 3.3 \\
\hline Child welfare + Disability pension & 181 & 0.3 & 89 & 0.3 & 92 & 0.3 \\
\hline Child welfare + Disability pension with psychiatric diagnosis & 135 & 0.2 & 68 & 0.2 & 67 & 0.2 \\
\hline
\end{tabular}

Note: Persons who died before 18 years of age were excluded from the figures.

Original population 59,476 , of which 30,435 are boys and 29,041 are girls.

The results from the logistic regression analyses are shown in Tables 2a-2c. We present odds ratios (ORs) and their $95 \%$ confidence intervals (95\% $\mathrm{Cl}$ ). In the first model, including child welfare experience as the only covariate, we find a statistically significant association between child protection history and DP status (Table $2 a$, joint model for boys and girls). Compared to children without child welfare experience, individuals who have been subject to child welfare measures are overrepresented as DP recipients. The odds ratios in the model are 7.36 for boys (Table 2b) and 5.02 for girls (Table 2c). 
Table 2a. Associations between DP and child welfare experience and covariates, including OR and 95\% confidence intervals. Both genders' significant OR (0.05 level) in bold. Persons who died before 18 years of age and persons with DP with F70-79 diagnosis were excluded from the figures.

\begin{tabular}{|c|c|c|c|c|c|c|c|c|c|c|c|c|c|c|c|c|}
\hline & \multirow[t]{2}{*}{$\mathrm{N}$} & \multicolumn{3}{|l|}{ Model 1} & \multicolumn{3}{|c|}{ Model 2} & \multicolumn{3}{|c|}{ Model 3} & \multicolumn{3}{|c|}{ Model 4} & \multicolumn{3}{|c|}{ Model 5} \\
\hline & & $\mathrm{OR}$ & Lower & Upper & OR & Lower & Upper & $\mathrm{OR}$ & Lower & Upper & OR & Lower & Upper & OR & Lower & Upper \\
\hline Child welfare & 1861 & 6.02 & 4.98 & 7.28 & 4.38 & 3.52 & 5.44 & & & & & & & 4.56 & 3.68 & 5.64 \\
\hline Parents' social assistance & 21234 & & & & 1.43 & 1.22 & 1.68 & 1.63 & 1.39 & 1.90 & & & & & & \\
\hline Mother's psych. in-/outpatient care & 3796 & & & & 1.15 & 0.90 & 1.45 & 1.37 & 1.09 & 1.73 & & & & & & \\
\hline Father's psych. in-/outpatient care & 3031 & & & & 1.42 & 1.11 & 1.83 & 1.54 & 1.20 & 1.97 & & & & & & \\
\hline Mother's psychiatric DP & 907 & & & & 1.81 & 1.28 & 2.57 & 2.32 & 1.65 & 3.26 & & & & & & \\
\hline Mother's somatic DP & 969 & & & & 1.52 & 0.99 & 2.34 & 1.51 & 0.98 & 2.31 & & & & & & \\
\hline Father's psychiatric DP & 1173 & & & & 1.34 & 0.93 & 1.92 & 1.43 & 1.00 & 2.05 & & & & & & \\
\hline Father's somatic DP & 2115 & & & & 1.28 & 0.93 & 1.74 & 1.28 & 0.94 & 1.75 & & & & & & \\
\hline Mother's death & 595 & & & & 0.58 & 0.31 & 1.08 & 0.82 & 0.44 & 1.51 & & & & & & \\
\hline Father's death & 1755 & & & & 1.08 & 0.78 & 1.49 & 1.23 & 0.89 & 1.70 & & & & & & \\
\hline Divorce & 13327 & & & & 1.14 & 0.98 & 1.34 & 1.17 & 1.00 & 1.37 & & & & & & \\
\hline \multicolumn{17}{|l|}{ Mother's highest education } \\
\hline High school or higher (ref.) & 9383 & & & & & & & & & & & & & & & \\
\hline Lowest level tertiary & 13604 & & & & 0.89 & 0.71 & 1.13 & 0.89 & 0.70 & 1.12 & & & & & & \\
\hline Lower secondary & 26600 & & & & 0.90 & 0.72 & 1.11 & 0.91 & 0.73 & 1.13 & & & & & & \\
\hline Primary & 9291 & & & & 0.94 & 0.73 & 1.22 & 1.06 & 0.82 & 1.37 & & & & & & \\
\hline \multicolumn{17}{|l|}{ Father's highest education } \\
\hline High school or higher (ref.) & 10657 & & & & & & & & & & & & & & & \\
\hline Lowest level tertiary & 8121 & & & & 0.92 & 0.71 & 1.18 & 0.90 & 0.70 & 1.16 & & & & & & \\
\hline Lower secondary & 25560 & & & & 0.81 & 0.66 & 1.00 & 0.81 & 0.66 & 1.00 & & & & & & \\
\hline Primary & 14540 & & & & 0.72 & 0.57 & 0.91 & 0.77 & 0.61 & 0.97 & & & & & & \\
\hline Mother below 20 years old & 1884 & & & & 1.08 & 0.78 & 1.50 & 1.24 & 0.90 & 1.71 & & & & & & \\
\hline Parents' cumulative risk, 0 (ref.) & 21832 & & & & & & & & & & 1.00 & & & 1.00 & & \\
\hline Parents' cumulative risk, 1-2 & 26768 & & & & & & & & & & 1.28 & 1.08 & 1.51 & 1.20 & 1.02 & 1.42 \\
\hline Parents' cumulative risk, 3-4 & 8773 & & & & & & & & & & 2.22 & 1.84 & 2.68 & 1.70 & 1.39 & 2.07 \\
\hline Parents' cumulative risk, 5-9 & 1505 & & & & & & & & & & 3.90 & 2.93 & 5.19 & 2.06 & 1.50 & 2.82 \\
\hline
\end{tabular}


Table 2b. Associations between DP and child welfare experience and covariates, including OR and $95 \%$ confidence intervals for boys. Significant OR ( 0.05 level) in bold. Persons who died before 18 years of age and persons with DP with F70-79 diagnosis were excluded from the figures.

\begin{tabular}{|c|c|c|c|c|c|c|c|c|c|c|c|c|c|c|c|c|}
\hline & \multirow[t]{2}{*}{$\mathrm{N}$} & \multicolumn{3}{|c|}{ Model 1} & \multicolumn{3}{|c|}{ Model 2} & \multicolumn{3}{|c|}{ Model 3} & \multicolumn{3}{|c|}{ Model 4} & \multicolumn{3}{|c|}{ Model 5} \\
\hline & & & Lower & Upper & OR & Lower & Upper & OR & Lower & Upper & OR & Lower & Upper & OR & Lower & Upper \\
\hline Child welfare & 914 & 7.36 & 5.62 & 9.65 & 4.88 & 3.55 & 6.71 & & & & & & & 5.47 & 4.01 & 7.45 \\
\hline Parents' social assistance & 10813 & & & & 1.78 & 1.39 & 2.27 & 2.00 & 1.58 & 2.54 & & & & & & \\
\hline Mother's psych. in-/outpatient care & 1820 & & & & 1.23 & 0.87 & 1.75 & 1.56 & 1.11 & 2.19 & & & & & & \\
\hline Father's psych. in-/outpatient care & 1485 & & & & 1.39 & 0.96 & 2.02 & 1.49 & 1.02 & 2.16 & & & & & & \\
\hline Mother's psychiatric DP & 469 & & & & 2.08 & 1.29 & 3.34 & 2.68 & 1.69 & 4.26 & & & & & & \\
\hline Mother's somatic DP & 492 & & & & 0.73 & 0.30 & 1.80 & 0.74 & 0.30 & 1.81 & & & & & & \\
\hline Father's psychiatric DP & 632 & & & & 1.38 & 0.83 & 2.29 & 1.58 & 0.96 & 2.60 & & & & & & \\
\hline Father's somatic DP & 1087 & & & & 0.99 & 0.59 & 1.66 & 1.01 & 0.61 & 1.69 & & & & & & \\
\hline Mother's death & 304 & & & & 0.39 & 0.12 & 1.26 & 0.53 & 0.17 & 1.69 & & & & & & \\
\hline Father's death & 881 & & & & 0.95 & 0.57 & 1.59 & 1.09 & 0.66 & 1.82 & & & & & & \\
\hline Divorce & 6719 & & & & 1.18 & 0.93 & 1.49 & 1.22 & 0.96 & 1.54 & & & & & & \\
\hline \multicolumn{17}{|l|}{ Mother's highest education } \\
\hline High school or higher (ref.) & 4801 & & & & & & & & & & & & & & & \\
\hline Lowest level tertiary & 6899 & & & & 0.86 & 0.61 & 1.23 & 0.86 & 0.60 & 1.22 & & & & & & \\
\hline Lower secondary & 13655 & & & & 0.93 & 0.67 & 1.29 & 0.95 & 0.69 & 1.32 & & & & & & \\
\hline Primary & 4732 & & & & 0.97 & 0.66 & 1.43 & 1.13 & 0.77 & 1.65 & & & & & & \\
\hline \multicolumn{17}{|l|}{ Father's highest education } \\
\hline High school or higher (ref.) & 5449 & & & & & & & & & & & & & & & \\
\hline Lowest level tertiary & 4169 & & & & 0.80 & 0.55 & 1.14 & 0.78 & 0.54 & 1.12 & & & & & & \\
\hline Lower secondary & 13074 & & & & 0.59 & 0.44 & 0.81 & 0.60 & 0.44 & 0.82 & & & & & & \\
\hline Primary & 7395 & & & & 0.57 & 0.40 & 0.80 & 0.62 & 0.44 & 0.88 & & & & & & \\
\hline Mother below 20 years old & 961 & & & & 0.92 & 0.56 & 1.51 & 1.12 & 0.69 & 1.83 & & & & & & \\
\hline Parents' cumulative risk. 0 (ref.) & 11260 & & & & & & & & & & 1.00 & & & 1.00 & & \\
\hline Parents' cumulative risk. 1-2 & 13657 & & & & & & & & & & 1.42 & 1.10 & 1.83 & 1.33 & 1.03 & 1.71 \\
\hline Parents' cumulative risk. 3-4 & 4398 & & & & & & & & & & 2.49 & 1.86 & 3.31 & 1.80 & 1.33 & 2.45 \\
\hline Parents' cumulative risk. 5-9 & 772 & & & & & & & & & & 4.70 & 3.10 & 7.13 & 2.15 & 1.35 & 3.43 \\
\hline
\end{tabular}


Table 2c. Associations between DP and child welfare experience and covariates, including OR and $95 \%$ confidence intervals for girls. Significant OR ( 0.05 level) in bold. Persons who died before 18 years of age and persons with DP with F70-79 diagnosis were excluded from the figures.

\begin{tabular}{|c|c|c|c|c|c|c|c|c|c|c|c|c|c|c|c|c|}
\hline & \multirow[t]{2}{*}{$\mathrm{N}$} & \multicolumn{3}{|c|}{ Model 1} & \multicolumn{3}{|c|}{ Model 2} & \multicolumn{3}{|c|}{ Model 3} & \multicolumn{3}{|c|}{ Model 4} & \multicolumn{3}{|c|}{ Model 5} \\
\hline & & & Lower & Upper & OR & Lower & Upper & OR & Lower & Upper & OR & Lower & Upper & OR & Lower & Upper \\
\hline Child welfare & 947 & 5.02 & 3.85 & 6.55 & 3.98 & 2.94 & 5.38 & & & & & & & 3.87 & 2.89 & 5.19 \\
\hline Parents' social assistance & 10421 & & & & 1.21 & 0.98 & 1.51 & 1.38 & 1.12 & 1.70 & & & & & & \\
\hline Mother's psych. in-/outpatient care & 1976 & & & & 1.05 & 0.75 & 1.46 & 1.20 & 0.87 & 1.66 & & & & & & \\
\hline Father's psych. in-/outpatient care & 1546 & & & & 1.43 & 1.02 & 2.00 & 1.56 & 1.12 & 2.17 & & & & & & \\
\hline Mother's psychiatric DP & 438 & & & & 1.52 & 0.89 & 2.58 & 1.90 & 1.13 & 3.19 & & & & & & \\
\hline Mother's somatic DP & 477 & & & & 2.15 & 1.31 & 3.52 & 2.12 & 1.30 & 3.47 & & & & & & \\
\hline Father's psychiatric DP & 541 & & & & 1.29 & 0.76 & 2.19 & 1.30 & 0.77 & 2.19 & & & & & & \\
\hline Father's somatic DP & 1028 & & & & 1.52 & 1.03 & 2.25 & 1.51 & 1.02 & 2.23 & & & & & & \\
\hline Mother's death & 291 & & & & 0.76 & 0.36 & 1.58 & 1.08 & 0.52 & 2.25 & & & & & & \\
\hline Father's death & 874 & & & & 1.19 & 0.78 & 1.81 & 1.33 & 0.88 & 2.03 & & & & & & \\
\hline Divorce & 6608 & & & & 1.12 & 0.90 & 1.39 & 1.13 & 0.91 & 1.40 & & & & & & \\
\hline \multicolumn{17}{|l|}{ Mother's highest education } \\
\hline High school or higher (ref.) & 4582 & & & & & & & & & & & & & & & \\
\hline Lowest level tertiary & 6705 & & & & 0.91 & 0.67 & 1.24 & 0.90 & 0.66 & 1.23 & & & & & & \\
\hline Lower secondary & 12945 & & & & 0.86 & 0.64 & 1.16 & 0.87 & 0.65 & 1.16 & & & & & & \\
\hline Primary & 4559 & & & & 0.92 & 0.65 & 1.30 & 1.01 & 0.72 & 1.42 & & & & & & \\
\hline \multicolumn{17}{|l|}{ Father's highest education } \\
\hline High school or higher (ref.) & 5208 & & & & & & & & & & & & & & & \\
\hline Lowest level tertiary & 3952 & & & & 1.04 & 0.74 & 1.47 & 1.03 & 0.73 & 1.45 & & & & & & \\
\hline Lower secondary & 12486 & & & & 1.04 & 0.78 & 1.39 & 1.05 & 0.78 & 1.39 & & & & & & \\
\hline Primary & 7145 & & & & 0.87 & 0.63 & 1.21 & 0.92 & 0.67 & 1.28 & & & & & & \\
\hline Mother below 20 years old & 923 & & & & 1.24 & 0.80 & 1.91 & 1.34 & 0.87 & 2.06 & & & & & & \\
\hline Parents' cumulative risk. 0 (ref.) & 10572 & & & & & & & & & & 1.00 & & & 1.00 & & \\
\hline Parents' cumulative risk. 1-2 & 13111 & & & & & & & & & & 1.17 & 0.94 & 1.46 & 1.12 & 0.90 & 1.39 \\
\hline Parents' cumulative risk. 3-4 & 4375 & & & & & & & & & & 2.02 & 1.57 & 2.60 & 1.62 & 1.24 & 2.10 \\
\hline Parents' cumulative risk. 5-9 & 733 & & & & & & & & & & 3.34 & 2.25 & 4.97 & 1.98 & 1.29 & 3.05 \\
\hline
\end{tabular}


In Model 2, we include parental social assistance recipiency, parental psychiatric health variables, parental DP variables and other background characteristics. Child protection experience, parental social assistance, father's psychiatric care, mother's psychiatric DP, and father's low level of education are statistically significant in the model for the entire cohort. For boys, the statistically significant factors are child protection experience, parental social assistance, mother's psychiatric DP, and father's lowest and second-lowest educational level. In the model for girls, the statistically significant factors are child protection experience, father's psychiatric care, and mother's and father's somatic DP.

In the third model, we investigate the relationship between background characteristics excluding the child welfare experience. The results are mostly similar to the previous model, but the ORs are slightly higher. In the model for the entire cohort, mother's psychiatric care is statistically significant when the child welfare experience is not accounted for. For boys, both mother's and father's psychiatric care are statistically significant factors in this model. The difference in the model for girls compared to the previous model is that parental social assistance and mother's psychiatric DP are statistically significant factors.

To examine the effect of the accumulation of risk factors on DP, we estimated logistic regression analyses with only accumulated risk factors (Model 4) and risk factors and child welfare experience (Model 5) as covariates. Model 4 reveals that there is a statistically significant relationship between the accumulation of risk factors and DP. For individuals with parents with 1-2 risk factors, compared to those without any risk factors, the ORs for DP are 1.28 (entire cohort), 1.42 (boys) and 1.17 (girls, insignificant). An increase in risk factors involves an increase in ORs. For individuals with parents with 59 risk factors, the ORs are 3.90 (whole cohort), 4.70 (boys) and 3.34 (girls).

The final model involves accumulated risk variables and child welfare experience. Including the child welfare variable lowers the ORs for the risk factor variables. However, other than the cumulative risk with 1-2 risk factors among girls, all the cumulative risk variables are statistically significant. Children with child welfare experience are more likely to have DP. The ORs for those with child welfare experience compared to those without child welfare experience are 4.56 for the entire cohort, 5.47 for boys and 3.87 for girls.

To summarise the main findings from Tables $2 a-$ 2c, we find that child welfare experience has a statistically significant association with DP since ORs for the entire cohort are considerable. Parental social assistance has a statistically significant association with DP among boys, but it loses its significance in the model with the most controls among girls. Furthermore, mother's psychiatric DP makes a difference for boys, whereas father's psychiatric care and both father's and mother's somatic DP are statistically significant factors for girls. Parents' accumulated risk factors are important, and the more risk factors there are, the larger the OR is.

Finally, to investigate whether specific psychiatric diagnoses are more common DP grounds among individuals with child welfare experience than among those without that experience, we show several statistically significant differences between individuals with and without child welfare experience in Table 3 . We use $\chi^{2}$ tests to determine significant associations and ORs to indicate how strong the association is. For instance, girls with child welfare experience are more likely to receive DP than are girls without child welfare experience for all of the grounds except mania/bipolar disorder. Compared to those without child welfare experience, girls with that experience have an OR of 7.32 for having DP due to neurotic, stress-related and somatoform disorders. For boys, the pattern is very similar except that no statistically significant difference is found regarding neurotic, stress-related and somatoform disorders. There is no statistically significant difference regarding other psychiatric diagnoses among boys. Schizophrenia and schizotypal and delusional disorders have an OR of 10.12 and are the DP ground among boys, among whom child welfare clients most strongly differ from those without that experience. Multiple diagnoses also have a large OR for both genders, indicating that compared to those without child welfare experience, child welfare clients are clearly more prone to having DP due to multiple diagnoses. 


\section{Table 3. Crosstabs with OR and $\chi^{2}$ tests (Fisher's Exact Test is reported when assumptions for $\chi^{2}$ tests are not fulfilled)}

\begin{tabular}{|c|c|c|c|c|c|c|c|c|c|c|c|c|c|c|c|c|c|c|c|c|c|c|c|c|c|c|c|c|c|c|c|c|c|c|c|c|c|c|}
\hline \multirow[b]{2}{*}{ All } & & \multicolumn{4}{|c|}{ Disability pension } & \multicolumn{4}{|c|}{$\begin{array}{l}\text { Schizophrenia. schizotypal } \\
\text { and delusional disorders }\end{array}$} & \multicolumn{4}{|c|}{ Mania/bipolar disorder } & \multicolumn{4}{|c|}{$\begin{array}{l}\text { Depression and mood } \\
\text { disorders }\end{array}$} & \multicolumn{4}{|c|}{$\begin{array}{l}\text { Neurotic. stress-related } \\
\text { and somatoform disorders }\end{array}$} & \multicolumn{4}{|c|}{ Other diagnoses } & \multicolumn{4}{|c|}{ Multiple diagnoses } & \multicolumn{4}{|c|}{ Intellectual disability } & \multicolumn{4}{|c|}{ Other than F-diagnoses } & \multirow[t]{2}{*}{ Total } \\
\hline & & No & $\begin{array}{l}\text { Yes } \\
\mathrm{N}\end{array}$ & $\begin{array}{l}\text { Yes } \\
\%\end{array}$ & $\begin{array}{l}O R \\
p x^{2}\end{array}$ & No & $\begin{array}{l}\text { Yes } \\
\text { N }\end{array}$ & $\begin{array}{l}\text { Yes } \\
\%\end{array}$ & $\begin{array}{l}\mathrm{OR} \\
\mathrm{p} x^{2}\end{array}$ & No & $\begin{array}{l}\text { Yes } \\
\mathrm{N}\end{array}$ & $\begin{array}{l}\text { Yes } \\
\%\end{array}$ & $\begin{array}{l}\mathrm{OR} \\
\mathrm{p} \mathrm{x}^{2}\end{array}$ & No & $\begin{array}{l}\text { Yes } \\
\text { N }\end{array}$ & $\begin{array}{l}\text { Yes } \\
\%\end{array}$ & $\begin{array}{l}O R \\
p x^{2}\end{array}$ & No & $\begin{array}{l}\text { Yes } \\
\mathrm{N}\end{array}$ & $\begin{array}{l}\text { Yes } \\
\%\end{array}$ & $\begin{array}{l}\mathrm{OR} \\
\mathrm{p} x^{2}\end{array}$ & No & $\begin{array}{l}\text { Yes } \\
\mathrm{N}\end{array}$ & $\begin{array}{l}\text { Yes } \\
\%\end{array}$ & $\begin{array}{l}\mathrm{OR} \\
\mathrm{p} \mathrm{x}^{2}\end{array}$ & No & $\begin{array}{l}\text { Yes } \\
\mathrm{N}\end{array}$ & $\begin{array}{l}\text { Yes } \\
\%\end{array}$ & $\begin{array}{l}\text { OR } \\
\mathrm{p} \mathrm{x}^{2}\end{array}$ & No & $\begin{array}{l}\text { Yes } \\
\mathrm{N}\end{array}$ & $\begin{array}{l}\text { Yes } \\
\%\end{array}$ & $\begin{array}{l}\mathrm{OR} \\
\mathrm{px^{2 }}\end{array}$ & No & $\begin{array}{l}\text { Yes } \\
\mathrm{N}\end{array}$ & $\begin{array}{l}\text { Yes } \\
\%\end{array}$ & $\begin{array}{l}\mathrm{OR} \\
\mathrm{p} x^{2}\end{array}$ & \\
\hline & No & 56034 & 1191 & 2.08 & 4. & 57037 & 188 & 0.33 & 7. & 57163 & 62 & 0.11 & & 57045 & 180 & 0.31 & & 7179 & 46 & 0.08 & & 57134 & 91 & 0.16 & & 57061 & 164 & 0.29 & & 57017 & 208 & 0.36 & & 6973 & 252 & 0.44 & 93 & 57225 \\
\hline & es & 1710 & 181 & 9.57 & & 1844 & 47 & 2.49 & $<c$ & 1886 & 5 & 0.26 & & 1866 & 25 & 1.32 & & 1882 & 9 & 0.48 & & 1877 & 14 & 0.74 & & 1856 & 35 & 1.85 & & 1861 & 30 & 1.59 & & 1875 & 16 & 0.85 & .01 & 1891 \\
\hline Total & & 57744 & 1372 & 2.32 & & 58881 & 235 & 0.40 & & 59049 & 67 & 0.11 & & 58911 & 205 & 0.35 & & 59061 & 55 & 0.09 & & 59011 & 105 & 0.18 & & 58917 & 199 & 0.34 & & 58878 & 238 & 0.40 & & 58848 & 268 & 0.45 & & 59116 \\
\hline bys & & & & & & & & & & & & & & & & & & & & & & & & & & & & & & & & & & & & & & \\
\hline child & No & 28711 & 579 & 1.98 & 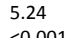 & 29184 & 106 & 0.36 & 10.12 & 29270 & 20 & 0.07 & 1.5 & 29229 & 61 & 0.21 & & 29272 & 18 & 0.06 & 3. & 29238 & 52 & 0.18 & & 29232 & 58 & 0.20 & & 29173 & 117 & 0.40 & & 29143 & 147 & 0.50 & 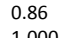 & 29290 \\
\hline & Yes & 842 & 89 & 9.56 & & 898 & 33 & 3.54 & & 930 & 1 & 0.11 & & 922 & 9 & 0.97 & & 929 & 2 & 0.21 & & 922 & 9 & 0.97 & & 917 & 14 & 1.50 & $<c$ & 914 & 17 & 1.83 & 01 & 927 & 4 & 0.43 & b & 931 \\
\hline Total & & 29553 & 668 & 2.21 & & 30082 & 139 & 0.46 & & 30200 & 21 & 0.07 & & 30151 & 70 & 0.23 & & 30201 & 20 & 0.07 & & 30160 & 61 & 0.20 & & 30149 & 72 & 0.24 & & 30087 & 134 & 0.44 & & 30070 & 151 & 0.50 & & 30221 \\
\hline Girls & & & & & & & & & & & & & & & & & & & & & & & & & & & & & & & & & & & & & & \\
\hline & $\mathrm{N}$ & 27323 & 612 & 2.19 & & 27853 & 82 & 0.29 & & 27893 & 42 & 0.15 & & 27816 & 119 & 0.43 & & 27907 & 28 & 0.10 & & 27896 & 39 & 0.14 & & 27829 & 106 & 0.38 & & 27844 & 91 & 0.33 & & 27830 & 105 & 0.38 & & 27935 \\
\hline & s & 868 & 92 & 9.58 & & 946 & 14 & 1.46 & & 956 & 4 & 0.42 & 0.066 & 944 & 16 & 1.67 & & 953 & 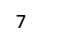 & 0.73 & & 955 & 5 & 0.52 & & 939 & 21 & 2.19 & 01 & 947 & 13 & 1.35 & 01 & 948 & 12 & 1.25 & 001 & 960 \\
\hline otal & & 28191 & 704 & 2.44 & & 28799 & 96 & 0.33 & & 28849 & 46 & 0.16 & & 28760 & 135 & 0.47 & & 28860 & 35 & 0.12 & & 28851 & 4 & 0.15 & & 2876 & 127 & 0.44 & & 28791 & 104 & 0.36 & & 2877 & 117 & 0.40 & & 28895 \\
\hline
\end{tabular}

Note: Persons who died before 18 years of age were excluded from the figures.

OR from binary logistic regression model without controls. Comparison group is individuals without child welfare experience.

Disability pension (DP on any of the grounds).

Schizophrenia, schizotypal and delusional disorders (DP based on only these psychiatric diagnoses; may involve somatic diagnoses).

Mania/bipolar disorder (DP based on only these psychiatric diagnoses; may involve somatic diagnoses).

Depression and mood disorders (DP based on only these psychiatric diagnoses; may involve somatic diagnoses).

Neurotic, stress-related and somatoform disorders (DP based on only these psychiatric diagnoses; may involve somatic diagnoses).

Other diagnoses (DP based on other psychiatric grounds, excluding intellectual disability (F70-79); may involve somatic diagnoses).

Multiple diagnoses (DP based on at least two of the psychiatric diagnoses above; may involve somatic diagnoses).

Intellectual disability (involves all who have received DP with diagnoses related to intellectual disability (F70-79); may also involve other psychiatric or somatic diagnoses).

Other than F-diagnoses (DP based only on somatic diagnoses). 
To summarise the results in Table 3, children with child welfare experience are more likely than children without that experience to be granted DP on certain psychiatric grounds, such as schizophrenia, schizotypal and delusional disorders, depression and mood disorders, and neurotic, stress-related and somatoform disorders (girls only).

\section{Discussion}

Mental disorders are major grounds for DP in Finland. Even though most DPs are fixed-term, individuals who start on DP typically depart from the workforce permanently. Mental health and behavioural issues are the main reasons for DP among the younger DP recipients in Finland. Young DP recipients are problematic because the efficient functioning of the welfare state depends substantially on high labour market participation. The Finnish welfare state is already challenged by a population structure with large cohorts on their way to retirement and an unemployment level that is higher than it should be. Thus, there is substantial political concern regarding the working ability of the working-age population. The reasons for entry into DP among younger people are of great interest for both the research community and for those involved in decision-making, policy design and policy implementation.

This study aimed to investigate psychiatric diagnoses as grounds for DP among child welfare clients and to explore the background factors that are associated with psychiatric diagnoses and DP. Therefore, we reviewed the grounds for DP in a Finnish cohort. We investigated the grounds for DP in this cohort in general, but we also focused on a particularly vulnerable group, children who have been placed outside their homes by the child protection authorities. We found that these individuals are more prone to DP on psychiatric grounds than are individuals without that history. As previous research indicates, the impact of the accumulation of risk factors during childhood is essential even for this cohort. The accumulation of risk factors during childhood was found to be a statistically significant factor explaining DP in young adulthood. Furthermore, we investigated specific psychiatric diagnoses as grounds for a DP decision. To our knowledge, this is a novel undertaking because no previous studies have investigated psychiatric diagnoses as grounds for DP among individuals with a child protection history. Individuals with child welfare experience were overrepresented as DP recipients with regard to most of the specific psychiatric diagnoses as DP grounds.

We found a gender difference in the psychiatric grounds for DP. Schizophrenia, schizotypal and delusional disorders were more common grounds for DP among boys, whereas depression and mood disorders were more common grounds for DP among girls. This finding is not surprising because we know from previous research that women are clearly more prone to depressive disorders than men are. Similarly, we know that schizophrenia is somewhat more common among men than among women. Compared to those without child welfare experience, girls with that experience were clearly more prone to having DP due to neurotic, stressrelated and somatoform disorders. Schizophrenia and schizotypal and delusional disorders is the DP ground among boys, among whom child welfare clients most strongly differ from those without that experience. Multiple diagnoses also have a strong association for both genders, indicating that child welfare clients are clearly more prone to obtain DP due to multiple diagnoses than individuals without that experience.

Schizophrenia has a substantial hereditary component, and there is a need for more detailed investigations relating to this group. We cannot draw more accurate conclusions based on the analysis conducted in this paper. However, we recognise that a closer investigation of the grounds on which child welfare officers based their decisions to place these children outside their homes may shed light on the pathways between child welfare clients' childhood histories and their DP. Currently, this information is not available in national registers due to difficulties in defining and classifying the reasons for out-of-home placement.

The results in this paper are consistent with previous empirical and theoretical research regarding cumulative advantage and disadvantage. Our results show that children whose parents have psychiatric or somatic problems for which they are on DP are also more likely to have a psychiatric diagnosis or to become a DP recipient in young adulthood. This intergenerational transmission of disadvantages is well established in the literature, and our findings support theories related both to the intergenerational transmission of inequality and 
cumulative disadvantage. We also find that cumulative parental risk factors increase the risk for psychiatric DP, confirming the importance of cumulative risk factors.

Moreover, our results are in line with studies showing that socioeconomic circumstances during childhood are related to adult health status. Previous research shows that the probabilities for DP and participation in other welfare programs are higher for those individuals whose parents participated in these programs. Similarly, our results show that DP has a statistically significant association with both parental social assistance receipt and parental DP. More detailed analyses that involve an attempt to separate socially and biologically inherited behaviours and qualities would be an interesting but complex task.

There might also be interesting interactions between being outside the labor force and mental health, and the mechanisms behind these life course trajectories are of considerable interest. There are likely multiple reasons why individuals with a difficult path to adulthood fail in their transition to the labour market. For example, the roles that they have learned at home may involve learned helplessness or a lack of social skills and behaviours that are needed to function in the labour market. However, previous research has also shown that the economic stress that is related to unemployment is harmful to mental health (cf. Barr, Kinderman, \& Whitehead, 2015). Thus, an individual who has satisfactory labour market prospects but for some reason fails in the transition to the labour market may experience economic stress due to unemployment, and this stress, in turn, has negative effects on mental health. The interconnections between these phenomena are obviously complex. Detailed investigations should therefore be undertaken, such as examining the role of mediating and moderating factors, including the ability of social and educational services to ameliorate the effects of challenging childhood conditions.

A child welfare history that includes out-of-home care indicates that there were severe problems in the home environment during upbringing. Our findings confirm previous research showing that when the number of risk factors increases, the dangerousness of the effects increases as well. Thus, exposure to multiple risks seems to have lasting effects on individuals. Future research should also consider whether the age when the outof-home care occurs makes a difference for child welfare clients and their long-term outcomes. Are there critical periods related to out-of-home care? This is a difficult question to answer because there may be many different mechanisms, including selection mechanisms, that affect the outcome.

\section{Limitations}

Our variable information does not include any information about why the child was placed. From previous research, we know that reasons for placement for teenagers often involve a complex mixture of behavioural and school-related difficulties that may or may not involve psychiatric conditions. Further research is needed to completely rule out reverse causality.

There are also reasons to believe that some psychiatric diseases are underdiagnosed. It may be difficult to seek medical help for these because of social stigma, and those cases of psychiatric illness would not be identified in this study. Child welfare clients may also have less trust in the authorities, including medical practitioners, and their tendency to seek help may differ from the behaviour of individuals without child welfare experience. 


\section{Acknowledgements}

This paper has benefitted from comments at a seminar at Norwegian Social Research in Oslo and at a meeting organised by the Nordic network on register-based child welfare research in Stockholm. The usual disclaimer applies.

This study was supported by two grants from the Academy of Finland, grant number 288960 (Time trend changes of child and adolescent mental health, service use and well-being in multiple Finnish cohorts) and grant number 308552 (PSYCHORT). The work also benefited from two personal grants from the Finnish Work Environment Fund and Alli Paasikivi Foundation (Tiina Ristikari).

The Finnish Birth Cohort 1987 study obtained a positive statement from the research ethical committee of the National Institute for Health and Welfare (Ethical committee \$28/2009), and permissions to use the register data was obtained from all register holding organisations.

\section{References}

Barr, B., Kinderman, P., \& Whitehead, M. (2015). Trends in mental health inequalities in England during a period of recession, austerity and welfare reform 2004 to 2013. Social Science and Medicine, 147, 324-331. https://doi.org/10.1016/j.socscimed.2015.11.009

Bask, M., \& Bask, M. (2015). Cumulative (dis)advantage and the Matthew effect in life-course analysis. PLoS ONE, 10(11), e0142447. https://doi.org/10.1371/journal.pone.0142447

Bask, M., Ferrer-Wreder, L., Salmela-Aro, K., \& Bergman, L. R. (2014). Pathways to educational attainment in middle adulthood: the role of gender and parental educational expectations in adolescence. In J. S. Eccles, \& I. Schoon (Eds.), Gender differences in aspirations and attainment: a life course perspective (pp. 389-411). Cambridge, UK: Cambridge University Press.

https://doi.org/10.1017/СВ09781139128933.023

Ben-Shlomo, Y., \& Kuh, D. (2002). A life course approach to chronic disease epidemiology: conceptual models, empirical challenges and interdisciplinary perspectives. International Journal of Epidemiology, 31(2), 285-293. https://doi.org/10.1093/intjepid/31.2.285

Berlin, M., Vinnerljung, B., \& Hjern, A. (2011). School performance in primary school and psychosocial problems in young adulthood among care leavers from long term foster care. Children and Youth Services Review, 33(12), 2489-2497. https://doi.org/10.1016/j.childyouth.2011.08.024

Bowen, M. E., \& González, H. M. (2010). Childhood socioeconomic position and disability in later life: results of the health and retirement study. American Journal of Public Health, 100, S197-S203. https://doi.org/10.2105/AJPH.2009.160986

Bratberg, E., Nilsen, $\varnothing$. A., \& Vaage, K. (2015). Assessing the intergenerational correlation in disability pension recipiency. Oxford Economic Papers, 67(2), 205-226. https://doi.org/10.1093/oep/gpu028

Chen, E., Matthews, K. A., \& Boyce, W. T. (2002). Socioeconomic differences in children's health: how and why do these relationships change with age? Psychological Bulletin, 128(2), 295-329. https://doi.org/10.1037/0033-2909.128.2.295

Cohen, S., Janicki-Deverts, D., Chen, E., \& Matthews, K. A. (2010). Childhood socioeconomic status and adult health. Annals of the New York Academy of Sciences, 1186, 37-55. https://doi.org/10.1111/j.17496632.2009.05334.x

Costello, E. J., Erkanli, A., Copeland, W., \& Angold, A. (2010). Association of family income supplements in adolescence with development of psychiatric and substance use disorders in adulthood among an American Indian population. JAMA, 303(19), 1954-1960. https://doi.org/10.1001/jama.2010.621

Crystal, S., \& Shea, D. (1990). Cumulative advantage, cumulative disadvantage, and inequality among elderly people. Gerontologist, 30(4), 437-443. https://doi.org/10.1093/geront/30.4.437

Dahl, G. B., Kost $\varnothing l$, A. R., \& Mogstad, M. (2014). Family welfare cultures. Quarterly Journal of Economics, 129(4), 1711-1752. https://doi.org/10.1093/qje/qju019

Doyle, J. J. Jr. (2007). Child protection and child outcomes: measuring the effects of foster care. American Economic Review, 97(5), 1583-1610. https://doi.org/10.1257/aer.97.5.1583 
ETK. (2015). Statistical yearbook of pensioners in Finland. Accessed July 8, 2017, from http://www.etk.fi/wpcontent/uploads/Statistical_yearbook_of_pensioners_in_Finland_2014.pdf

ETK. (2017). Disability pension. Accessed July 8, 2017, from http://www.etk.fi/en/the-pension-system-2/thepension-system/pension-benefits/earnings-related-pensions/disability-pension/

Evans, G. W., \& Cassells, R. C. (2014). Childhood poverty, cumulative risk exposure, and mental health in emerging adults. Clinical Psychological Science, 2(3), 287-296. https://doi.org/10.1177/2167702613501496

Evans, G. W., Li, D., \& Whipple, S. S. (2013). Cumulative risk and child development. Psychological Bulletin, 139(6), 1342-1396. https://doi.org/10.1037/a0031808

Farand, L., Chagnon, F., Renaud, J., \& Rivard, M. (2004). Completed suicides among Quebec adolescents involved with juvenile justice and child welfare services. Suicide and Life-Threatening Behavior, 34(1), 24-35.

Franzén, E., Vinnerljung, B., \& Hjern, A. (2008). The epidemiology of out-of-home care for children and youth: a national cohort study. British Journal of Social Work, 38(6), 1043-1059. https://doi.org/10.1093/bjsw/bcl380

Harkonmäki, K., Korkeila, K., Vahtera, J., Kivimäki, M., Suominen, S., Sillanmäki, L., \& Koskenvuo, M. (2007). Childhood adversities as a predictor of disability retirement. Journal of Epidemiology and Community Health, 61(6), 479-484. https://doi.org/10.1136/jech.2006.052670

Heneghan, A., Stein, R. E. K., Hurlburt, M. S., Zhang, J., Rolls-Reutz, J., Fisher, E., Landsverk, J., \& Horwitz, S. M. (2013). Mental health problems in teens investigated by U.S. child welfare agencies. Journal of Adolescent Health, 52(5), 634-640. https://doi.org/10.1016/j.jadohealth.2012.10.269

Jackson, S., \& Cameron, C. (2012). Leaving care: looking ahead and aiming higher. Children and Youth Services Review, 34(6), 1107-1114. https://doi.org/10.1016/j.childyouth.2012.01.041

Kestilä, L., Väisänen, A., Paananen, R., Heino, T., \& Gissler, M. (2012). Kodin ulkopuolelle sijoitetut nuorina aikuisina: rekisteripohjainen seurantatutkimus Suomessa vuonna 1987 syntyneistä [Children placed in out-of-home care as young adults. A register-based follow-up study on children born in 1987 in Finland]. Yhteiskuntapolitiikka, 77, 599-620.

Laaksonen, M., Blomgren, J., \& Tuulio-Henriksson, A. (2016). Sickness allowance histories among disability retirees due to mental disorders: a retrospective case-control study. Scandinavian Journal of Public Health, 44(3), 291-299. https://doi.org/10.1177/1403494815618314

Lynch, J., \& Smith, G. D. (2005). A life course approach to chronic disease epidemiology. Annual Review of Public Health, 26, 1-35. https://doi.org/10.1146/annurev.publhealth.26.021304.144505

Mersky, J. P., \& Janczewski, C. (2013). Adult well-being of foster care alumni: comparisons to other child welfare recipients and a non-child welfare sample in a high-risk, urban setting. Children and Youth Services Review, 35(3), 367-376. https://doi.org/10.1016/j.childyouth.2012.11.016

Mykletun, A., Overland, S., Dahl, A. A., Krokstad, S., Bjerkeset, O., Glozier, N., Aarø, L. E., \& Prince, M. (2006). A population-based cohort study of the effect of common mental disorders on disability pension awards. American Journal of Psychiatry, 163(8), 1412-1418.

https://doi.org/10.1176/ajp.2006.163.8.1412

Najman, J. M., Hayatbakhsh, M. R., Clavarino, A., Bor, W., O'Callaghan, M. J., \& Williams, G. M. (2010). Family poverty over the early life course and recurrent adolescent and young adult anxiety and depression: a longitudinal study. American Journal of Public Health, 100(9), 1719-1723.

https://doi.org/10.2105/AJPH.2009.180943

Organisation for Economic Co-operation and Development. (2014). OECD economic surveys: Finland 2014. Accessed July 8, 2017, from http://www.oecd-ilibrary.org/economics/oecd-economic-surveysfinland-2014_eco_surveys-fin-2014-en

Paananen, R., Ristikari, T., Merikukka, M., \& Gissler, M. (2013). Social determinants of mental health: a Finnish nationwide follow-up study on mental disorders. Journal of Epidemiology and Community Health, 67(12), 1025-1031. https://doi.org/10.1136/jech-2013-202768 
Reiss, F. (2013). Socioeconomic inequalities and mental health problems in children and adolescents: a systematic review. Social Science and Medicine, 90, 24-31. https://doi.org/10.1016/j.socscimed.2013.04.026

Ristikari, T., Hakovirta, M., \& Gissler, M. (2016). The impact of timing and duration of parental social assistance receipt on early adult outcomes. Manuscript submitted for publication.

THL. (2014a). Lastensuojelu 2014 [Child welfare 2014]. Accessed July 8, 2017, from http://www.julkari.fi/bitstream/handle/10024/129537/Tr25_15.pdf?sequence=4

THL. (2014b). Liitetaulukko 1. Kodin ulkopuolelle sijoitetut lapset ja nuoret viimeisimmän sijoitustiedon mukaan, 2012-2014 [Children and young people placed outside the home based on the last placement decision, 2012-2014]. Accessed July 8, 2017, from https://www.thl.fi/tilastoliite/tilastoraportit/2015/liitetaulukot/Tr25_15_liite1.xls

Upmark, M., Lundberg, I., Sadigh, J., \& Bigert, C. (2001). Conditions during childhood and adolescence as explanations of social class differences in disability pension among young men. Scandinavian Journal of Public Health, 29(2), 96-103. https://doi.org/10.1177/14034948010290020601

Upmark, M., \& Thundal, K. L. (2002). An explorative, population-based study of female disability pensioners: the role of childhood conditions and alcohol abuse/dependence. Scandinavian Journal of Public Health, 30(3), 191-199. https://doi.org/10.1177/140349480203000305

Verbrugge, L. M., \& Jette, A. M. (1994). The disablement process. Social Science and Medicine, 38(1), 1-14. https://doi.org/10.1016/0277-9536(94)90294-1

Vinnerljung, B., Brännström, L., \& Hjern, A. (2015). Disability pension among adult former child welfare clients: a Swedish national cohort study. Children and Youth Services Review, 56, 169-176. https://doi.org/10.1016/j.childyouth.2015.07.001

Vinnerljung, B., Hjern, A., \& Lindblad, F. (2006). Suicide attempts and severe psychiatric morbidity among former child welfare clients - a national cohort study. Journal of Child Psychology and Psychiatry, 47(7), 723-733. https://doi.org/10.1111/j.1469-7610.2005.01530.x 